\title{
Using GIS Methods in Spatial Modelling of Climatic Water Balance Index
}

\author{
Agnieszka WYPYCH \\ ${ }^{1}$ Jagiellonian University, Krakow/Poland · agnieszka.wypych@uj.edu.pl \\ This contribution was double-blind reviewed as full paper.
}

\begin{abstract}
The main aim of this study is to find the best spatialization method to describe spatial differentiation of climatic water balance (CWB) in Poland. Monthly mean values of air temperature and precipitation totals from 60 synoptic stations as well as monthly totals of solar radiation (23 measuring points) were taken into consideration. Source material covered period 1985-2006. Regarding the prior research as well as data availability the potential evapotranspiration data was calculated by Turc formula.

CWB modelling was conducted with two methods simultaneously: simple and multiple linear regression (with latitude, altitude and distance from the coast line as variables), and map algebra. Validation proved the map algebra to be the better of the two spatialization methods. Nevertheless the obtained results proved also that except for the method local factors are of the great importance in CWB modelling especially in the mountains and at the coast. To optimize the method it is necessary to reduce the research scale using more insitu data that would enable inclusion of more local variables such as land form and land cover into the analyses.
\end{abstract}

\section{Introduction}

Recent development of GIS techniques has produced a wide range of powerful methods for modelling and displaying of climatological and meteorological data. Advanced processing methods allow for detailed analysis of climate elements at different temporal and spatial scales. GIS techniques designed to consider temperature and atmospheric precipitation have received the most attention so far (TVEITO et al. 2008). However, researchers are often interested not in meteorological elements themselves but in the information that can be extracted from them in form of various indices, which are useful in environmental and human sciences (TVEITO et al. 2008).

One of such indices, presenting a basis of a climatic assessment of water resources of a given area, is a climatic water balance (CWB). It focuses on the difference between the precipitation and evapotranspiration. The knowledge of spatial distribution of the climatic water balance seems to be very important according to its comprehensive application in spatial management, agriculture and hydroclimatological modelling. Nevertheless it has not been a subject of detailed analyses so far, mainly because the climatic water balance and its 
spatialization is very complex. It is, first and foremost, a subject associated with a problem of spatial interpolation of evapotranspiration, which varies considerably with changes in the natural environment. Secondly, it relates to a problem of data availability. Given the complicated nature of the subject, it is no wonder that there exist many GIS methods that attempt to model the spatial differentiation of evapotranspiration (e.g. NOVÁKY 2002, XiNFA et al. 2002, FERNANDES et al. 2007, ViCENTE-SERRANO et al. 2007). Also remote sensing techniques are becoming more commonly used to address this research issue and often supplement ground-based observations (RosEMA 1990, KALMA et al. 2008).

The aim of this study is to develop a new methodology for climatic water balance index implementation using geographical information systems (GIS) in cases when there is no appropriate spatial information given from in-situ observations. The specific objectives are: (1) to find out which spatialization method is the most appropriate to be used regarding both complex index of climatic water balance and also the data deficiency, (2) to assess an error magnitude as well as advantages and defects of all the methods implemented, (3) to state which explanatory variables (predictors) could be used according to the research area and time scale (with monthly and annual resolution). All of these seem to be really important when long-term analyses are taken into account as well as climate modelling.

\section{Data}

Although climatic water balance is quite a simple index to compute, complexity of evapotranspiration process due to influencing factors, like moisture content of the atmosphere, wind speed or land cover makes it really difficult to obtain exact values of CWB for meteorological (current) analyses. However, for climatological purposes (long term or general analyses) the value of evapotranspiration with a high precision can also be evaluated by the use of simplified models, which include meteorological elements that are normally measured by the meteorological stations.

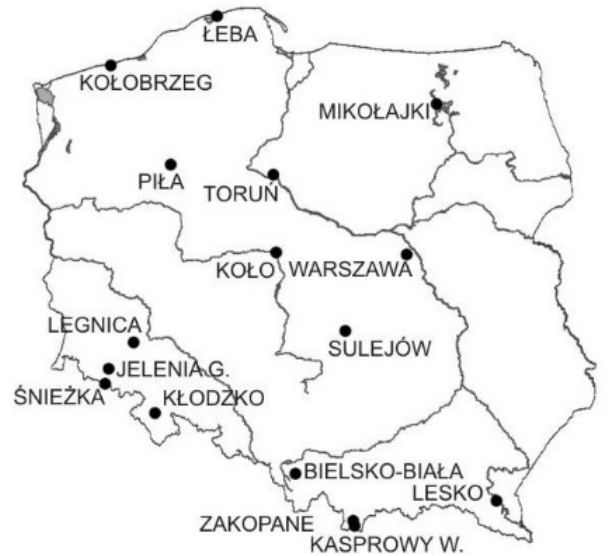

Fig. 1:

Location of stations across Poland used in the study

Therefore analyses of the climatic water balance (CWB) are usually developed for regions where input data, mainly air temperature and precipitation, can be obtained from meteorological stations. 
The study area covers whole territories of Poland which is located in the Central Europe Poland's relief has a parallel latitudinal scheme of the principal types of landscape. The beltlike layout of the main landscape regions is favourable to free zone circulation. At the same time, the southern part of the country possesses relatively diverse relief, which impacts local weather and climate conditions. This also appears on the Polish coast where the Baltic Sea activity is apparent in many weather events. The factors mentioned above as well as the land location make it possible to observe significant weather differences across Polish territory.

The research presented herein is based on mean monthly values of air temperature and precipitation totals obtained from 60 meteorological stations as well as monthly totals of solar radiation coming from 21 solar stations. The data cover the periods 1951-2006 and 1986-2006 respectively. Not all solar stations considered collect necessary meteorological data, therefore for the detailed analyses of climatic water balance only the data from 16 stations and covering the period from 1986 to 2005 were used (figure 1).

Meteorological data was completed using topographical information from the SRTM DEM model (EROS 2011) and land use obtained from CORINE Land Cover (CLC) database (EEA 2011). Due to effective data processing for the detailed analysis both the SRTM DEM and the CLC 2000 were resampled into $1 \mathrm{~km}$ spatial resolution.

\section{Methods for spatialisation of climatic water balance}

Although the climatic water balance (CWB) is a complex index dependant on many variables it was created based on a simplified definition where it is interpreted as the difference between the precipitation totals (RR) and potential evapotranspiration (PET). Given the limited nature of the source data Turc's formula (1961) was used to obtain potential evapotranspiration values. This method is confirmed (KOWANETZ 2000) to be suitable for describing the relationships between evapotranspiration and relief. The final formula is given as follows:

$$
C W B=R R-0.4 \frac{t}{t+15} I+50
$$

where:

$\mathrm{RR}$ - monthly precipitation totals [mm]

$\mathrm{t}$ - monthly average air temperature $\left[{ }^{\circ} \mathrm{C}\right]$

$\mathrm{I}-$ monthly sum of total solar radiation $\left[\mathrm{cal} \mathrm{cm}^{-2} \mathrm{day}^{-1}\right]$

Climatic water balance modelling was carried out using two approaches simultaneously: linear regression method (FOTHERIGHAM et al. 2002) and the map algebra (TOMLIN 1990). Results of both were validated with common error estimators. The CWB values calculated for the 16 stations were used as the reference data (figure 1).

The analysis was conducted for growing season treated as the period from May until October, which is one of the most frequently used in agrometeorology. 


\subsection{Regression models}

First approach postulated using regression models: simple linear regression (SLR) and multiple linear regression (MLR) (FOTHERIGHAM et al. 2002). Close relationships between climatic water balance and geographical factors became the basis of the model with longitude, latitude, altitude as well as distance from the coast and land cover as explanatory variables.

Because of the limited number of samples and also the least (from all the analysed predictors) correlation coefficient between CWB values and longitude (table 1) as well as small differentiation of land cover at measuring points it was finally decided to exclude those variables from regression models (2-4) and not use them in further analyses:

$$
\begin{aligned}
& \mathrm{Z}(\mathrm{s})=\beta 0+\beta 2 \mathrm{H}(\mathrm{s})+\varepsilon(\mathrm{s}) \\
& \mathrm{Z}(\mathrm{s})=\beta 0+\beta 1 \varphi(\mathrm{s})+\beta 2 \mathrm{H}(\mathrm{s})+\varepsilon(\mathrm{s}) \\
& \mathrm{Z}(\mathrm{s})=\beta 0+\beta 1 \varphi(\mathrm{s})+\beta 2 \mathrm{H}(\mathrm{s})+\beta 3 \mathrm{~d}(\mathrm{~s})+\varepsilon(\mathrm{s})
\end{aligned}
$$

where:

$\mathrm{Z}(\mathrm{s})$ - dependant variable

$\varphi(s)$ - latitude,

$\mathrm{H}(\mathrm{s})$ - altitude (m a.s.l.)

$\mathrm{d}(\mathrm{s})$ - distance from the coast $(\mathrm{m})$

$\varepsilon(s)$ - regression residuals

Table 1: Pearson's correlation coefficient values (R) between CWB index and selected predictors; values statistically significant at $\alpha=0.05$ level bolded

\begin{tabular}{|c|c|c|c|c|c|c|c|}
\hline Predictor* & May & June & July & Aug. & Sept. & Oct. & $\begin{array}{c}\text { May- } \\
\text { Oct. }\end{array}$ \\
\hline$\lambda$ & -0.131 & -0.216 & -0.126 & -0.234 & -0.193 & -0.370 & -0.212 \\
\hline$\varphi$ & 0.283 & 0.318 & 0.113 & 0.385 & 0.355 & $\mathbf{0 . 5 9 9}$ & 0.345 \\
\hline $\mathrm{H}$ & $\mathbf{0 . 8 6 4}$ & $\mathbf{0 . 8 5 3}$ & $\mathbf{0 . 8 4 1}$ & $\mathbf{0 . 8 6 4}$ & $\mathbf{0 . 8 6 2}$ & $\mathbf{0 . 9 1 1}$ & $\mathbf{0 . 8 7 8}$ \\
\hline $\mathrm{d}$ & 0.314 & 0.348 & 0.166 & 0.382 & 0.340 & 0.552 & 0.357 \\
\hline
\end{tabular}

$* \lambda$ - longitude; $\varphi$ - latitude; $\mathrm{H}$-altitude; $\mathrm{d}$-distance from the coast

The described linear dependences allowed to calculate CWB values for grid points delimited with the spatial resolution of $1 \mathrm{~km}$.

In the last step Radial Basis Functions (RBF) was used to create the map of climatic water balance spatial differentiation (figure 2). RBF was chosen as it is the exact interpolation technique, which takes into account the general tendencies and also local variability. Research conducted hitherto (WYPYCH \& USTRNUL 2011) has confirmed the applicability of RBF method also for CWB index spatialization. 


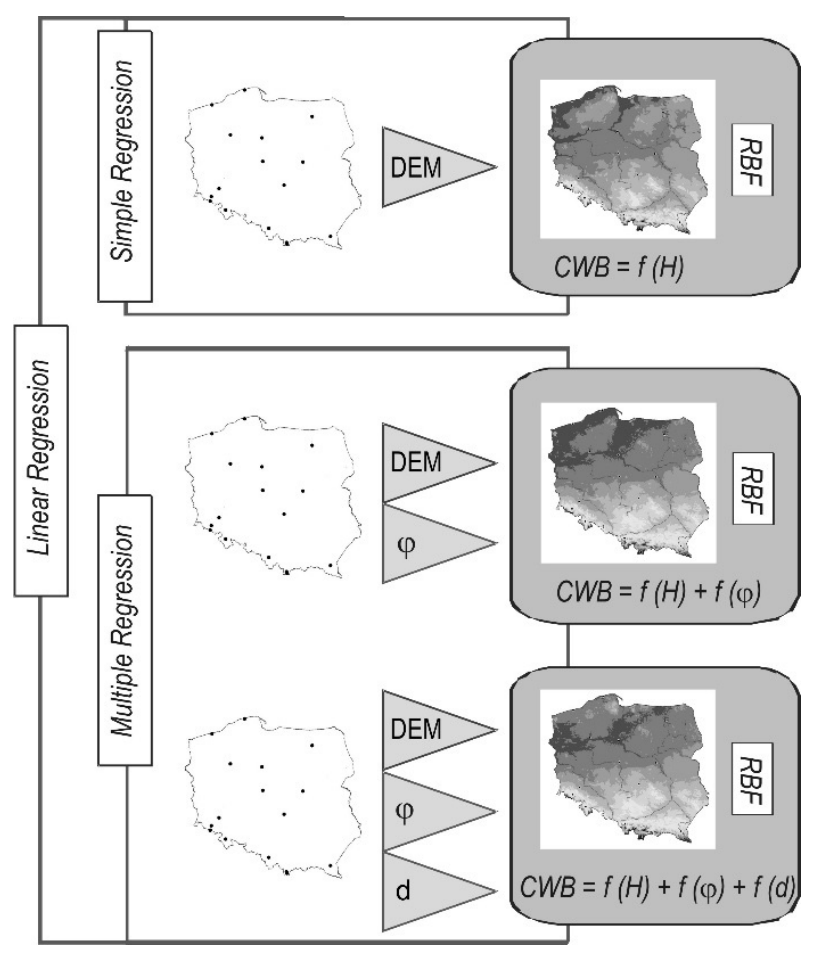

Fig. 2:

Workflow for the linear regression approach $(\varphi$ - latitude; $\mathrm{H}$ - altitude; $\mathrm{d}$ - distance from the coast)

\subsection{Map algebra}

The second approach was based on map algebra application. In the first step a set of maps presenting spatial distribution of climatic water balance index components: air temperature, precipitation totals and solar radiation was created using in-situ data (figure 3).

Component maps of the climatic water balance index were constructed according to a methodology developed by international research teams dealing with GIS implementation in meteorology and climatology (CHAPMAN \& THORNES 2003; DOBESCH et al. 2007). As first CWB component (figure 3), temperature spatial differentiation maps were created using residual kriging method (USTRNUL \& CZEKIERDA 2005). Several geographic parameters, including elevation, latitude, longitude, and distance to the Baltic coast (for stations located within $100 \mathrm{~km}$ ), were used as predictor variables for air temperature. Precipitation totals were interpolated over the area of Poland with ordinary kriging method (LUPIKASZA et al. 2007). The solar radiation surface has been obtained in by two stages. Firstly solar radiation field was generated with ordinary kriging method for the point data from 21 measuring stations. Simultaneously but independently the ArcGIS solar analyst application was used. All the necessary information was implemented, i.e. sun hours, attitude for the site area, radiation parameters (diffuse factor and transmittivity) and topographical factors: slope, aspect and shaded relief counted from SRTM. Real data map, because of limited number of measuring points (only 21 measuring stations across the country distributed irregularly), turned to be characterized by significant errors when compared to reference data, whereas solar analyst model gives less errors over the most area of Poland (besides the significant difference in the mountain areas which are the results of using terrain 
(STRM) as a variable). Therefore in final analyses in-situ data was used only as the reference data to select proper parameters and model estimation.

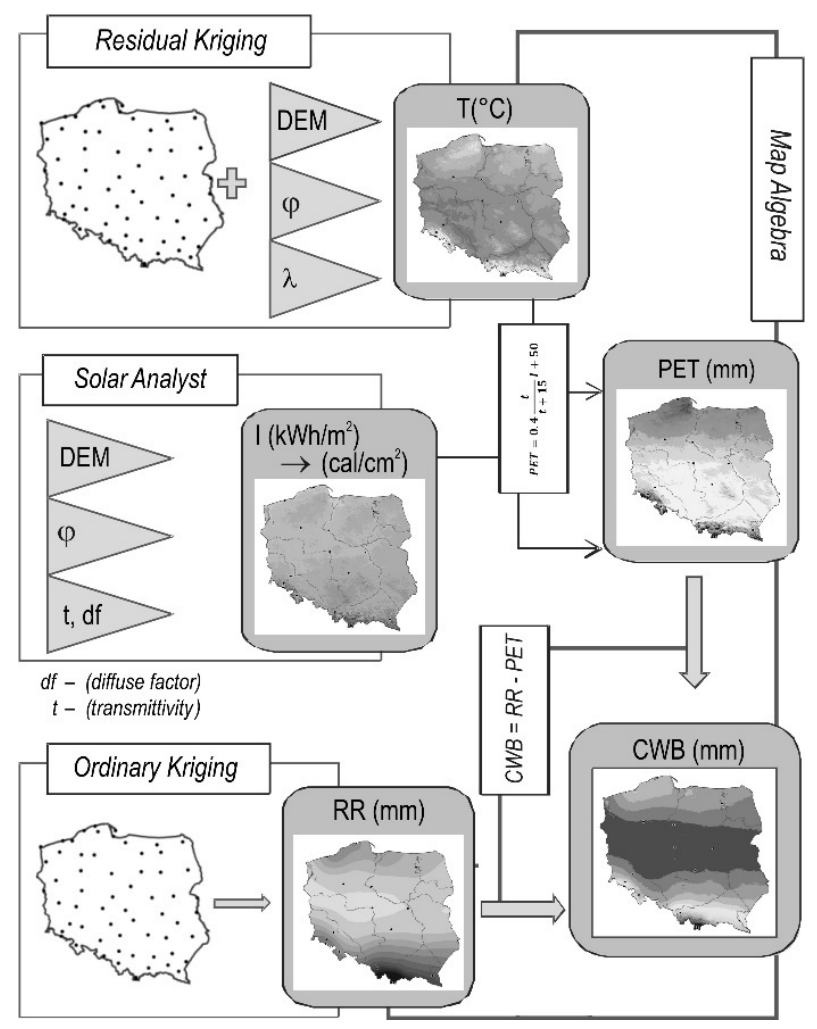

Fig. 3:

Workflow for the map algebra approach

$(\varphi$ - latitude; $\lambda$ - longitude;

$\mathrm{H}$ - altitude; $\mathrm{T}$ - temperature;

I - solar radiation;

RR - precipitation; PET potential evapotranspiration; CWB - climatic water balance)

All the layers created were used as an input data to potential evapotranspiration model by Turc's formula (air temperature together with solar radiation map) and further on with precipitation map to calculate climatic water balance for the area of Poland according to map algebra methodology (figure 3).

\subsection{Validation of the proposed methods}

The last step of CWB spatialisation was a validation of the proposed methods. Because of the very few reference points as well as implementing different interpolation methods only the common and unsophisticated statistical estimators were used: correlation coefficient between the real data (counted from in-situ measurements) and modelled data (R), bias (RE), percentage error (PE) and absolute error (AE). Within the last step of models validation also geostatistical estimators for spatial analyses were implemented: RMSE (root-mean square error), MPE (mean percentage error), and MAPE (mean absolute percentage error). All the model adjustment measures were implemented in relation to the values in the reference points. 


\section{Results}

Climatic water balance is a complex index being under influence of many different factors. Therefore the results are stuck mainly with those which modify both: precipitation and evapotranspiration values, e.g. solar radiation, relief and slope aspect, land use or even urbanization intensity.

Regression models produced in this study, mainly because of the significant correlation (compare with table 1), are determined by altitude (figure 2) whereas the map algebra model (MAG) shows also the importance of latitude and distance from the seashore reflecting the beltlike landscape (figure 3). Validation results well-mark that the map algebra (MAG) method is characterized by the smallest bias (figure 4). The highest - close to $1-$ correlation coefficient value confirms the best model adjustment; the absolute errors are also significantly smaller than in the other methods (table 2). Even though the model overestimates values for the region of north and central Poland giving the best prediction for north-eastern part of the country and the worst one for the central part (figure 4), it provides favourable effects for the mountains and coastal regions reducing the final model errors. These areas are mostly exposed to the impact of local factors and only the spatial resolution of MAG model, obtained through dense stations network, assures relatively unbiased final results.

Table 2: Selected model errors of climatic water balance values in growing season (May - October)

\begin{tabular}{|l|c|c|c|c|}
\hline Errors & MAG & SLR & MLR_1 & MLR_2 \\
\hline MAE $[\mathrm{mm}]$ & 48.6 & 82.0 & 83.0 & 75.5 \\
\hline RMSE $[\mathrm{mm}]$ & 86.1 & 102.5 & 95.3 & 88.3 \\
\hline MAPE $(\%)$ & 24.4 & 57.7 & 68.6 & 58.1 \\
\hline R & 0.988 & 0.940 & 0.937 & 0.950 \\
\hline
\end{tabular}

Regression models which do not take into consideration the distance from the seashore as the predictor (MLR 1) and simple regression (SLR) turned to be the weakest methods (table 2 , figure 4). It is worth noticing that spatial differentiation of the methods applicability is quite visible (figure 4). Simple linear regression (SLR) gives better results for the areas of the Baltic coast and in the Sudety mountains (at lowlands differences between methods cannot be clearly confirmed) whereas MLR_1 brings well-marked effects in the Carpathians (figure 4). 


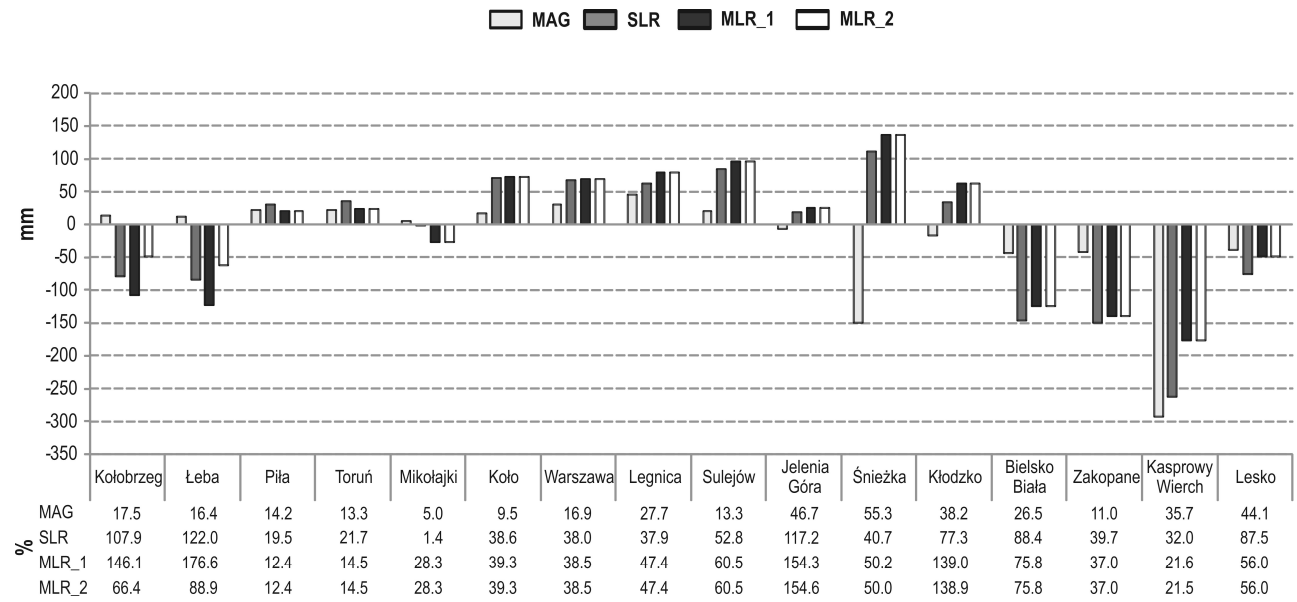

Fig. 4: Model errors [mm] and absolute percentage errors (\%) of CWB in growing season at reference points $\left(\mathrm{CWB}_{\text {mod }}-\mathrm{CWB}_{\text {ref }}\right)$; SLR - simple regression: $\mathrm{f}(\mathrm{H}), \mathrm{MLR} \_1$ multiple regression: $\mathrm{f}(\varphi, \mathrm{H}), \mathrm{MLR} \_2$ - multiple regression: $\mathrm{f}(\varphi, \mathrm{H}, \mathrm{d}), \mathrm{MAG}-$ map algebra

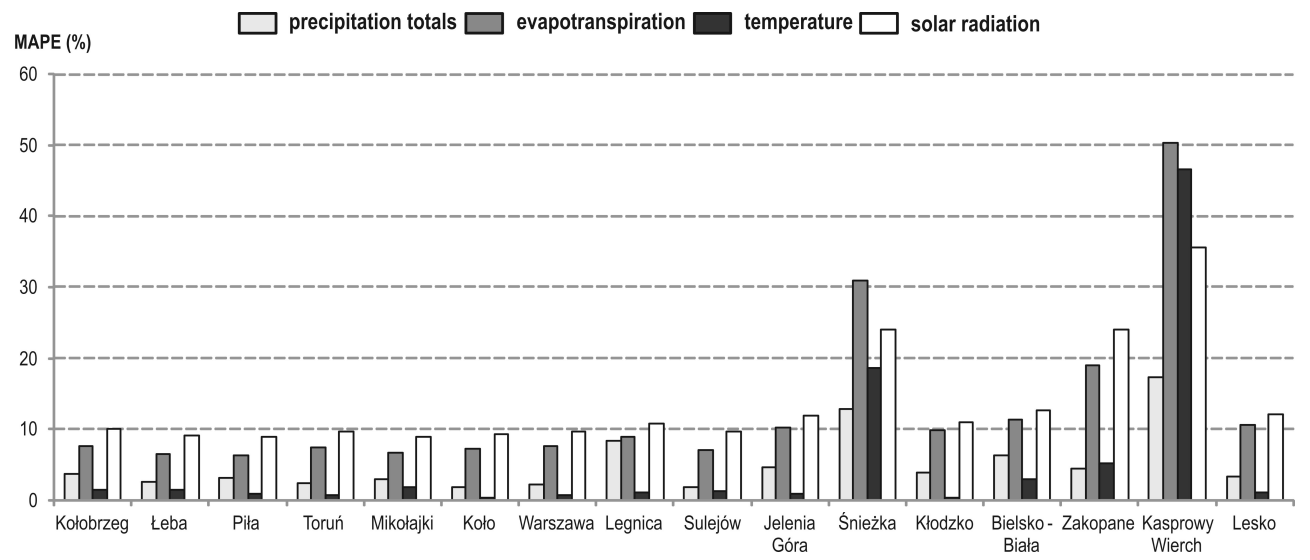

Fig. 5: Mean absolute percentage errors (\%) of CWB index components in growing season at reference points

As previously mentioned the MAG image is the effect of spatialization of different elements as precipitation and evapotranspiration, whereas the latter is a result of integrating solar radiation and temperature maps (figure 3). Therefore it could be assumed that these results are additionally laden with the partial errors of particular map components. Partial validation completed for every element field used (figure 5) shows that spatialization techniques worked out hitherto (compare to 3.2) give entirely satisfactory results while interpolating air temperature and precipitation totals. Percentage errors are the least in those cases (figure 5). The worst results, what was predictable, were obtained for solar radiation and potential evapotranspiration fields. It goes especially for mountain regions (figure 5). 


\section{Conclusions}

GIS techniques and methods give a possibility of data visualization in different spatial scales, image generalization by information selection to adapt to the scale of the display, as well as to modify all the interpolation parameters to improve the quality of destination surface. The research performed here confirms that they are also useful and promising tool for constructing maps of different climate elements and indices. Nevertheless it must be stated that there is no simple universal spatialization method which is relevant for different spatial and temporal scales, especially when spatialization is processed for the physiographically heterogeneous terrain. It might be the best to implement combined methods considering the individual local conditions.

Regardless of the validation results, the maps of climatic water balance spatial differentiation in Poland obtained in this study show some deficiencies of implemented methods. Regression models are affected mainly by the lack data used to create the formulas (taking into account long-term and homogenous data series of necessary meteorological elements). The fundamental sources of error were irregular location of measuring stations and subsequently limited number of representative points regarding various environmental conditions in Poland. It can be particularly seen along the coast but also in north-eastern part of the country and of course in the mountains. On the other hand, solar radiation field seems to be the vulnerable point for map algebra. The limitations of solar analyst application are mainly due to the differentiated and also very inconstant cloud cover in our geographical location, as well as to the stations network that is not dense enough to assure good interpolation results.

No matter how prosper the results, the key role in such a situation is tribute to the research experience and scientific intuition. Careful and detailed analysis is needed in this instance as well as the thorough knowledge of the physical processes connected with the complexity of the geographical environment. Both are necessary while choosing the predictors and later on any model validation where complex series of explanatory variables is used.

\section{References}

BARRY, R. G. (1992), Mountain weather and climate. London-New York, Routledge.

ChAPMAN, L. \& THORNES, E. (2003), The use of geographical information systems in climatology and meteorology. Progress in Physical Geography 27 (3), 313-330.

Dobesch, H., Dumolard, P. \& Dyras, I. (Eds.) (2007), Spatial Interpolation for Climate Data: the Use of GIS in Climatology and Meteorology. London, ISTE.

Earth Resources Observation and Science (EROS) Center (2011), http://earthexplorer.usgs.gov/ (December 2011).

ESRI (2001), ArcGIS Geostatistical Analyst: Statistical Tools for Data Exploration, Modeling and Advanced Surface Generation. ESRI White Paper. Redlands - New York.

European Environment Agency (2011), http://www.eea.europa.eu (September 2011).

Fernandes, R., Korolevych, V. \& WANG, S. (2007), Trends in land evapotranspiration over Canada for the period 1960-2000 based on in situ climate observations and a land surface model. Journal of Hydrometeorology, 8, 1016-1030. 
Fotheringham, A. S, BRunsdon, C. \& Charlton, M. E. (2002), Geographically Weighted Regression: The Analysis of Spatially Varying Relationships. Chichester, Wiley.

JAWORSKI, J. (2004), Evaporation in hydrological cycle of river basins. Warszawa, Polskie Towarzystwo Geofizyczne (in Polish).

KALMA, J. D., MCVICAR, T. R. \& MCCABE, M. F. (2008), Estimating land surface evaporation: A review of methods using remotely sensed surface temperature data. Surveys in Geophysics, 29 (4-5), 421-469.

KowANETZ, L. (2000), On the method of determining the climatic water balance in mountainous areas, with the example from Polish Carpathians. Zeszyty Naukowe UJ, Prace Geograficzne, 105, 137-164.

ŁUPIKASZA, E., USTRNUL, Z. \& CZEKIERDA, D. (2007), The role of explanatory variables in spatial interpolation of selected climate elements. Roczniki Geomatyki, 5 (1), 55-64.

NovÁKY, B. (2002), Mapping of mean annual actual evaporation on the example of Zagyva catchment area. Idöjárás, 106 (3-4), 227-238.

Rosema, A. (1990), Comparison of Meteosat-based rainfall and evapotranspiration mapping in the Sahel region. International Journal of Remote Sensing, 11 (12), 22992309.

TOMLIN, D. C. (1990), Geographic information systems and cartographic modelling. Englewood Cliffs, NJ, Prentice Hall.

TURC, L. (1961), Evaluation des besoins en eau d'irrigation, évapotranspiration potentielle. Annales Agronomiques, 12 (1), 13-49.

TVeito, O. E., WegehenKel, M., Wel van Der, F. \& Dobesch, H. (Eds.) (2008), The use of geographic information systems in climatology and meteorology. Final Report COST Action719, COST Office.

Ustrnul, Z. \& CZEKIERDA, D. (2005), Application of GIS for the development of climatological air temperature maps: an example from Poland. Meteorol. Appl., 12, 43-50.

Vicente-Serrano, S. M., LANJeri, S. \& López-Moreno, J. I. (2007), Comparison of different procedures to map reference evapotranspiration using geographical information systems and regression-based techniques. Int. J. Climatol., 27, 1103-1118.

WYPYCH, A. \& USTRNUL, Z. (2011), Spatial differentiation of the climatic water balance in Poland. Időjárás, 115 (1-2), 111-120.

XinfA, Q., YAN, Z. \& ChANGMing, L. (2002), A general model for estimating actual evaporation from non-saturated surfaces. Journal of Geographical Sciences, 12 (4), 479-484. 